\title{
Manifestaciones neurológicas asociadas a infección por Mycoplasma pneumoniae
}

\author{
ANA CHÁVEZ P., PERLA DAVID G., XIMENA NORAMBUENA R., \\ CARMEN MENDOZA N. y MARCELO JODORKOVSKY R.
}

\section{Neurological clinical manifestations associated to Mycoplasma pneumoniae infection}

Mycoplasma pneumoniae, a well known respiratory pathogen, causes several extrapulmonary manifestations, being neurological diseases the most frequent. We present an 8 year old girl, with prolonged fever of unknown origin associated to Mycoplasma pneumoniae complicated with acute disseminated encephalomyelitis (ADE). Other six cases of: aseptic meningitis (1), meningoencephalitis (1), Guillain Barré Syndrome (GBS) (1) and facial paralysis (3) are reported. Pathogenesis of neurological complications associated to $M$. pneumoniae infection remains unknown, hypothesizing that some of them are due to CNS mycoplasma invasion and those with prolonged prodroms, as ADE, GBS and tranverse myelitis, could be considered immune mediated diseases. In our institution, where mycoplasma PCR detection technics are unavailable, we use mycoplasma IgM antibodies (ELISA) measurement or ascending titers of specific IgG. The impact of antimicrobial treatment to control these neurological symptoms is unclear and prescription of immunomodulation therapy has been promoted by some experts.

Key words: Mycoplasma pneumoniae, Encephalomyelitis; Fever of unknown origin.

Palabras claves: Mycoplasma pneumoniae, Encefalomielitis, Síndrome febril prolongado.

Mycoplasma pneumoniae es un reconocido patógeno del aparato respiratorio, que produce infecciones altas y bajas de diversa severidad, y es también responsable de numerosas y variadas manifestaciones extrapulmonares, como miocarditis y pericarditis, anemia hemolítica y trombocitopenia, artritis y artralgias, hepatitis, pancreatitis, compromiso mucocutáneo diverso, además de manifestaciones neurológicas, que constituyen los cuadros extrapulmonares más frecuentes, determinando un amplio espectro clínico, desde irritación meníngea leve a enfermedad neurológica severa $^{1-3}$.

El objetivo de esta publicación es presentar una serie clínica de pacientes pediátricos con diversos cuadros neurológicos asociados con una infección por Mycoplasma pneumoniae, tratados en el Servicio de Pediatría del Hospital Dr. Exequiel González Cortés.

\section{Caso clínico 1}

Escolar de 8 años, sexo femenino, que presentó un cuadro febril de comienzo agudo $\left(41^{\circ} \mathrm{C}\right)$, acompañado de dolor abdominal, náuseas y dolor de extremidades inferiores que dificultaba la deambulación, lo que motivó su internación después de una semana de evolución y varias consultas ambulatorias. Durante su hospitalización evolucionó febril, con decaimiento, palidez y signología bronquial húmeda escasa; se extinguió el dolor de extremidades agregándose un exantema máculo papular. Los cultivos de sangre, orina

Hospital Dr. Exequiel González Cortés:

Servicio de Pediatría (ACP, PDG, XNR, MJR); Laboratorio de Microbiología (CMN).

Recibido: 1 octubre 2003

Aceptado: 26 mayo 2004 
y médula ósea fueron negativos, radiografía de tórax y de cavidades paranasales normales, reacción de aglutinación para salmonelas (Widal) negativa y mielograma normal. Inicialmente se planteó el diagnóstico de fiebre tifoidea y se inició tratamiento con cloranfenicol. La paciente continuó febril y el exantema progresó hasta hacerse generalizado. Por la evolución clínica y los exámenes se descartó el diagnóstico planteado inicialmente, suspendiéndose el cloranfenicol al quinto día.

El día 24 de evolución la paciente fue trasladada al Hospital Exequiel González Cortés en relativas buenas condiciones generales, activa, cooperadora, febril $\left(39^{\circ} \mathrm{C}\right)$, destacando la presencia de un exantema máculo papular generalizado, confluente e intensamente eritematoso. El resto del examen físico era normal, con deambulación y examen neurológico normales.

En la exploración de laboratorio destacaban hematocrito $27 \%$, leucocitos $10.700 / \mathrm{mm}^{3}$, (baciliformes $51 \%$, segmentados $7 \%$ y linfocitos $42 \%$ ); plaquetas normales y VHS $30 \mathrm{~mm} / \mathrm{h}$. PCR $173 \mathrm{mg} / \mathrm{l}$. $\mathrm{C}_{3} 173 \mathrm{mg} \%$ y $\mathrm{C}_{4} 22 \mathrm{mg} \%$. Se planteó un síndrome febril prolongado e infección por $M$. pneumoniae, por lo que se solicitó IgM específica (ELISA) que fue positiva en títulos de 1.471 $\mathrm{U} / \mathrm{ml}$. Se inició tratamiento con claritromicina.

La niña evolucionó con fiebre alta, compromiso del estado general y decaimiento progresivos, evaneciendo el exantema y apareciendo dolor osteoarticular intermitente, en diversas localizaciones y trastorno de la marcha que se atribuyó al dolor. Se inició el estudio de una posible artritis crónica juvenil y vasculitis primaria o secundaria a colagenopatía.

En los días siguientes se agregó tendencia al sopor, marcha en estepaje, hiperreflexia osteotendínea asociada a hipotrofia muscular gradual y en el examen neurológico se comprobó una disminución del campo visual por confrontación, lo que fue corroborado con la evaluación oftalmológica que reveló fondo de ojo normal, con un aumento de la mancha ciega y hemianopsia izquierda en la medición de campo visual. Exámenes de control mostraron una anemización progresiva con hematocrito $26 \%$; la VHS aumentó a $116 \mathrm{~mm} / \mathrm{h}$.

Se descartó el compromiso osteoarticular mediante un cintigrama óseo que fue normal y la determinación de anticuerpos antinucleares, anti ADN y anti ENA fue negativa. La TAC de cerebro mostró leve hipodensidad en la región occipital. Un EEG mostró ritmo basal lento, difuso, desorganizado. Velocidad de conducción nerviosa enlentecida en el territorio del cuadriceps izquier- do. Una segunda determinación de IgM para $M$. pneumoniae fue de $1.790 \mathrm{U} / \mathrm{ml}$.

En ese momento de la evolución, ante la existencia del compromiso cortical evidenciado por tendencia al sopor y un EEG con trazado eléctrico lento difuso, de un síndrome piramidal caracterizado por hiperreflexia osteotendínea, del compromiso medular manifestado por signos de denervación del cuadriceps izquierdo y de neuritis retrobulbar con compromiso del campo visual, se planteó la existencia de una encefalomielitis diseminada aguda (EDA). Para documentar este diagnóstico se realizó RM de cerebro que mostró hipointensidad en T1 en el lóbulo occipital derecho. Se investigó la aparición de bandas oligoclonales en sangre y LCR las que fueron negativas. La síntesis de IgG en LCR fue normal.

Se decidió con este planteamiento diagnóstico iniciar tratamiento con metilprednisolona (iv), en dosis de $30 \mathrm{mg} / \mathrm{kg} /$ día, la que se administró durante 3 días, obteniéndose una notoria respuesta favorable, con descenso de la fiebre a las 24 horas y rápida mejoría del estado general. En los dos a tres días siguientes se observó mejoría de la marcha, de los reflejos osteotendíneos y del campo visual. Se continuó tratamiento con metilprednisolona $0,7 \mathrm{mg} / \mathrm{kg} /$ día durante 30 días y posteriormente con dosis decrecientes hasta suspenderla.

Al cuarto día de tratamiento el EEG mostró menor lentitud difusa y reapareció una gradiente anteroposterior. La VHS descendió a $85 \mathrm{~mm} / \mathrm{h}$ y posteriormente a $45 \mathrm{~mm} / \mathrm{h}$ y la PCR a $65 \mathrm{mg} / \mathrm{l}$. Continuó su rápida mejoría hasta la normalización del examen clínico y de los parámetros de laboratorio, manteniéndose así en el seguimiento a 2 años.

\section{Caso 2}

Preescolar de sexo femenino, 5 años. Quince días antes de su ingreso inició cuadro de fiebre, coriza y tos, al que se agregó al undécimo día cefalea intensa, que motivó su hospitalización. Al ingreso estaba en regular estado general, febril, con intensa cefalea, signos de irritación meníngea y signología bronquial húmeda. La radiografía de tórax mostró infiltrado intersticial bilateral. El LCR tenía análisis químico normal, 295 células $/ \mathrm{mm}^{3}$ (51\% de segmentados). PCR normal. IgM específica para M. pneumoniae positiva 1.300 $\mathrm{U} / \mathrm{ml}$. Se diagnosticó una meningitis aséptica y trató con claritromicina. Su posterior evolución fue favorable. 


\section{Caso 3}

Escolar de sexo masculino, 6 años. Seis días antes de su ingreso inició coriza, tos, fiebre y vómitos. Al sexto día presentó una crisis convulsiva tónico-clónica generalizada, que motivó su internación. Ingresó en regulares condiciones generales, con signos de irritación meníngea, signología bronquial obstructiva y de consolidación basal izquierda. Durante su hospitalización presentó una nueva crisis convulsiva. El LCR, obtenido con un procedimiento traumático, arrojó un examen químico normal, 147 leucocitos $/ \mathrm{mm}^{3}$ (70\% polimorfonucleares). Rx tórax: infiltrado intersticial bilateral y consolidación basal izquierda. IgM específica para M. pneumoniae $1.832 \mathrm{U} /$ ml. PCR $74 \mathrm{mg} / \mathrm{l}$. EEG: trazado eléctrico lento, difuso. TAC de cerebro normal. Se diagnosticó una meningoencefalitis aguda siendo tratado con claritromicina y fenobarbital, con evolución favorable. Un EEG de control efectuado dos meses más tarde fue normal.

\section{Caso 4}

Preescolar de sexo masculino, 4 años 11 meses. Siete días antes de su internación inició un cuadro de coriza y tos y el día previo a ser hospitalizado, se agregó compromiso del estado general y paresia progresiva de extremidades inferiores. Al ingreso tenía signología bronquial obstructiva, paresia de extremidades inferiores, con hipotonía y arreflexia. Evolucionó con progresión del cuadro neurológico hacia una tetraparesia fláccida, compromiso respiratorio y de deglución. Un estudio de LCR realizado en la segunda semana reveló disociación albúmino/ citológica. IgM específica para $M$. pneumoniae $1.622 \mathrm{U} / \mathrm{ml}$. PCR normal. Se diagnosticó síndrome de Guillain Barré. Requirió ventilación mecánica y recibió inmunoglobulina i.v. y claritromicina. Evolucionó lentamente hasta la recuperación total.

\section{Casos 5, 6 y 7}

Tres escolares de sexo femenino, compañeras de curso, de 13 años, consultaron por presentar parálisis facial periférica de instalación aguda. Todas tenían antecedentes de cuadro febril los días anteriores, con cefalea y otalgia. La IgM específica para $M$. pneumoniae en todas ellas fue positiva $(1.595,1.664$ y $1.471 \mathrm{U} / \mathrm{ml})$. Evolucionaron con regresión total de su sintomatología en 45 a 60 días.

\section{Discusión}

Las manifestaciones extrapulmonares de infección por $M$. pneumoniae más frecuentes son las neurológicas, que se producen por compromiso del SNC o sistema nervioso periférico, determinando un amplio espectro de presentaciones, desde irritación meníngea leve a enfermedad neurológica severa ${ }^{1,4,5}$. Estas ocurren con mayor frecuencia en niños, generalmente entre 1 y 21 días después de haber comenzado con un cuadro respiratorio, aunque alrededor del $20 \%$ de los pacientes no tiene antecedentes de síntomas respiratorios previos ${ }^{4,6}$. Entre las manifestaciones neurológicas descritas con mayor frecuencia destacan meningoencefalitis, meningitis aséptica, encefalitis, mielitis transversa, ataxia cerebelosa aguda, psicosis, neuropatía de nervios craneanos y periféricos, síndrome de Guillain Barré, parálisis de Bell, sordera neurosensorial y EDA ${ }^{1-4,6-11}$. Este compromiso neurológico puede regresar totalmente o dejar déficit residual, que en ocasiones es severo. En la literatura médica se reporta una incidencia de 20 a $30 \%$ de secuelas neurológicas permanentes ${ }^{1,4}$.

La patogenia de las complicaciones neurológicas relacionadas con infección por $M$. pneumoniae es aún desconocida ${ }^{1-4,6,9,10}$. Se han postulado varios mecanismos, como la invasión directa del $\mathrm{SNC}$, hipótesis que se sustenta en la detección de M. pneumoniae en el LCR y en el tejido cerebral, mediante aislamiento y técnica de RPC, fenómeno que se ha postulado sería el responsable de aquellos cuadros con un pródromos breve, menor de 5 a 7 días $1,2,4,6-8,10$.

Lo más aceptado en la actualidad es que $M$. pneumoniae gatilla fenómenos autoinmunes ${ }^{1,5-7}$. Este agente es presentado a neutrófilos y macrófagos a través de receptores de superficie para dar inicio a la fagocitosis, activación de factores de complemento y liberación de citoquinas. La respuesta inflamatoria generada activa los mecanismos de respuesta linfocitaria más específica destinada a remover el antígeno microbiano a través de la producción de anticuerpos. Por este mecanismo se formarían complejos inmunes que se depositarían en las estructuras del SNC, explicando de esta manera aquellos casos en que no se logra demostrar la presencia del agente. Este mecanismo patogénico permite una mejor comprensión de aquellos síndromes neurológicos relacionados con respuesta autoinmune como EDA, síndrome de Guillain Barré y mielitis transversa, y probablemente corresponda a aquellos con síntomas prodrómicos de más de 5 a 7 días de duración ${ }^{1,2,4,6,7}$. También ha sido propuesta la pro- 
ducción de una toxina después del descubrimiento de una neurotoxina producida por M. neurolyticum; sin embargo, no se ha logrado identificar una toxina producida por M. pneumoniae pr, $^{1,26}$.

Establecer una asociación entre infección por M. pneumoniae y las manifestaciones neurológicas es complejo debido a que es difícil asegurar la existencia de una infección por este agente $\mathrm{y}$, por otra parte, la patogenia de estos cuadros neurológicos, como se ha comentado, aún no está aclarada.

La comprobación de esta infección se dificulta porque los métodos habituales de diagnóstico tienen escasa utilidad en clínica; debido a la ausencia de pared celular, Mycoplasma no es coloreable en la tinción de Gram y el cultivo no es posible efectuarlo en laboratorios clínicos pues requiere de medios especiales. Su crecimiento es lento y su rendimiento varía entre 40 y $80 \%{ }^{12}$. Se han desarrollado técnicas para detectar los antígenos mediante ELISA o sonda genética, de alta sensibilidad y especificidad, técnicas que no están disponibles de rutina. En los últimos años se ha incorporado la identificación del ADN mediante RPC, que ha demostrado gran utilidad en LCR; aún no está difundido su uso en Chile ${ }^{1,7,12}$.

El diagnóstico de infección por $M$. pneumoniae se basa en nuestro medio, de acuerdo a lo señalado, en pruebas serológicas, determinación de títulos de $\operatorname{IgG}$ e $\operatorname{IgM}^{4}$. La prueba estándar para determinar IgG es la FC, aunque también es posible efectuarla mediante IFI; en ambas se requiere dos muestras pareadas separadas por dos a tres semanas, lo que le resta utilidad para el diagnóstico clínico. La determinación de IgM, en cambio, tiene mayor utilidad clínica por requerir sólo una muestra. Se puede realizar mediante prueba inmunoenzimática y mediante IFI, métodos de alta sensibilidad y especificidad. ${ }^{1,4,7,9,13-15}$

Sin embargo, en los casos de compromiso extrapulmonar por $M$. pneumoniae y específicamente de SNC, el diagnóstico serológico puede verse dificultado por la poca respuesta en base a IgM, fenómeno que podría condicionar a su vez, según algunos autores, la invasión del neuroeje $\mathrm{e}^{4}$.

En la literatura médica reciente se reportan casos de infección por $M$. pneumoniae demostrada por detección de ADN (RPC) en LCR y/o en secreciones respiratorias, en los que la serología fue negativa, lo que podría atribuirse a una falta de sensibilidad del test serológico o a una escasa respuesta de anticuerpos específicos ${ }^{7}$. Por otra parte, se ha planteado que puede haber serología falsamente positiva, probablemente por reactividad cruzada con antígenos cerebrales humanos ${ }^{6}$.
En base a esto, para confirmar que $M$. pneumoniae sea el agente responsable de un cuadro neurológico sería necesario demostrar su presencia en secreciones respiratorias y/o LCR mediante cultivo o RPC ${ }^{7}$.

El tratamiento de las manifestaciones neurológicas asociadas a infección por M. pneumoniae, considerando que no está aclarada su patogenia, es controvertido. El uso de antimicrobianos estaría indicado sólo en aquellos cuadros con un pródromo menor a 5 ó 7 días, en los que se plantea que hay invasión directa del SNC por $M$. pneumoniae. En cambio, en aquellos cuadros con un pródromo más prolongado, probablemente producidos por un mecanismo autoinmune, la utilidad de los antimicrobianos es discutible y en ellos se ha planteado el uso de terapia inmunomoduladora $^{1,4,7,16-18}$.

Todos los casos clínicos de esta serie presentaron un cuadro respiratorio febril y en ellos se documentó una infección por $M$. pneumoniae mediante determinación de $\operatorname{IgM}$ por método inmunoenzimático (Tabla 1).

En el caso 1, la niña presentó, después de un mes de haber iniciado el cuadro febril, manifestaciones neurológicas caracterizadas por un compromiso de primera neurona que se expresó por un síndrome piramidal con hipertonía, hiperreflexia osteotendínea, marcha en estepaje, EEG con trazado eléctrico lento difuso, RM con hipointensidad en $\mathrm{T} 1$ en la región occipital derecha, además compromiso medular con signos de denervación del cuadriceps izquierdo y una neuritis retrobulbar con compromiso del campo visual en el examen clínico y estudio de campimetría, con fondo de ojo normal. Con este compromiso neurológico agudo en diversos niveles del SNC se configuró el diagnóstico de encefalomielitis aguda post infección por Mycoplasma.

La EDA, es un proceso inflamatorio, desmielinizante, de evolución aguda o subaguda, que se caracteriza por ser diseminado, monofásico y no hemorrágico ${ }^{11,19}$. Las manifestaciones neurológicas generalmente se presentan una a dos semanas y hasta 30 días después de un cuadro infeccioso, aunque en ocasiones no se encuentra este antecedente; ocasionalmente las manifestaciones neurológicas pueden presentarse desde diez días antes y hasta seis semanas después de una infección ${ }^{5}$.

Las causas más frecuentes de EDA, además de $M$. pneumoniae, son las infecciones inespecíficas del tracto respiratorio superior y la varicela, pero se asocia a muchas otras enfermedades infecciosas, como sarampión, parotiditis, rubéola, enterovirosis, mononucleosis infeccio- 
Tabla 1. Características de los casos clínicos

\begin{tabular}{|c|c|c|c|c|c|}
\hline & Caso 1 & Caso 2 & Caso 3 & Caso 4 & Casos 5, 6 y 7 \\
\hline Edad & 8 años & 5 años & 6 años & 4 años 11 meses & 13 años \\
\hline Sexo & $\mathrm{F}$ & $\mathrm{F}$ & M & M & $\mathrm{F}$ \\
\hline $\begin{array}{l}\text { Tiempo de evolución previa } \\
\text { a manifestaciones neurológicas }\end{array}$ & 30 días & 15 días & 6 días & 7 días & 8-14 días \\
\hline $\begin{array}{l}\text { Manifestaciones neurológicas } \\
\text { iniciales }\end{array}$ & $\begin{array}{c}\text { Hipertonía, } \\
\text { hiperreflexia, } \\
\text { marcha en estepaje }\end{array}$ & $\begin{array}{l}\text { Síndrome } \\
\text { meníngeo }\end{array}$ & $\begin{array}{l}\text { Convulsiones } \\
\text { tónico-clónicas }\end{array}$ & $\begin{array}{c}\text { Paresia } \\
\text { extremidades } \\
\text { inferiores } \\
\text { hipotonía, } \\
\text { hiporreflexia }\end{array}$ & Parálisis facial \\
\hline Síndrome neurológico & EDA* & Meningitis & $\begin{array}{l}\text { Meningo } \\
\text { encefalitis }\end{array}$ & $\begin{array}{l}\text { S. Guillain } \\
\text { Barré }\end{array}$ & Parálisis facial \\
\hline IgM M. pneumoniae $(\mathrm{U} / \mathrm{ml})$ & 1471 & 1300 & 1832 & 1622 & $1595 / 1664 / 1471$ \\
\hline
\end{tabular}

* EDA: encefalitis discriminada aguda.

sa, coqueluche, influenza A y B, adenovirosis, infección por herpes simplex o VHH-6, listeriosis y leptospirosis. También se ha reportado después de las inmunizaciones activas antirábica, sarampión, rubéola, coqueluche, influenza y tifoidea y tras la inmunización pasiva con suero antitetánico; de ellas, es la vacunación contra sarampión la que con mayor frecuencia se describe asociada a esta patología $a^{5,16}$.

El compromiso neurológico generalmente ocurre cuando el exantema desaparece y la fiebre inicial se resuelve, siendo las manifestaciones clínicas de EDA muy variadas. Pueden presentarse desde un cuadro muy leve o síndromes aislados, como neuritis óptica y mielitis transversa, hasta el cuadro típico que se caracteriza por un síndrome muy grave meningo-encefalo-mielítico, febril, de comienzo brusco, con cefalea, somnolencia, signos meníngeos y convulsiones tónico clónicas; en 24 horas puede progresar el compromiso de conciencia, llegando a estupor y coma y desarrollarse signos neurológicos multifocales, los que incluyen ataxia, paraplejía o tetraplejía, coreoatetosis, mioclonías, alteraciones extrapiramidales, pérdida de visión y alteración de esfínteres. Son característicos la hiporreflexia aguda seguida por hiperreflexia, espasticidad y signo de Babinski. Puede presentarse cualquier combinación de signos y síntomas por compromiso de la sustancia blanca. También se han descrito cuadros psicóticos ${ }^{5,11,16}$. Se han reportado casos fulminantes con hipertensión intracraneana, herniación tentorial y muerte en 72 horas. Sin embargo, lo más característico es que la evolución y progresión de las complicaciones neurológicas ocurra en días a semanas, comple- tándose en un mes. Posteriormente, empieza la recuperación, la que puede ser rápida y total ${ }^{5}$. Se describe que 15 a $20 \%$ de los casos diagnosticados como EDA corresponderían al primer brote de esclerosis múltiple (EM); ésta es una patología infrecuente en la edad pediátrica. La EDA generalmente presenta severo compromiso de cerebro, médula espinal y compromiso bilateral de nervio óptico en forma simultánea, mientras la EM generalmente presenta compromiso más focal del cerebro, médula o nervio óptico, manifestándose como un síndrome monosintomático: neuritis óptica o mielopatía subaguda 5 .

En todos los casos presentados, excepto aquellos con parálisis facial, una vez obtenida serología IgM específica positiva, se decidió usar macrólidos, a pesar de su indicación controvertida.

En el caso 1 con el planteamiento diagnóstico de encefalomielitis diseminada aguda se empleó metilprednisolona, observándose una rápida mejoría, lo que apoya la hipótesis de un mecanismo inmunológico como causa probable de este cuadro.

Comentario. Dada la amplia gama de manifestaciones neurológicas asociadas a infección por M. pneumoniae, es importante tener presente esta etiología al enfrentar cuadros neurológicos con causa difícil de establecer, especialmente cuando éstos son precedidos de un síndrome respiratorio febril, aunque en un $20 \%$ de ellos este antecedente no existe.

Sin embargo, considerando las limitaciones que tiene la serología, como todo método indirecto, tanto en sensibilidad como en especifici- 
dad, para confirmar el diagnóstico de esta infección, sería un gran aporte disponer de RPC para efectuar en sangre y/o LCR, único método que permitiría asegurar que este agente es el responsable de las manifestaciones neurológicas.

\section{Resumen}

Mycoplasma pneumoniae, reconocido patógeno respiratorio, es también responsable de numerosas y variadas manifestaciones extrapulmonares, siendo las neurológicas las más frecuentes. Se presenta el caso de una escolar de 8 años, con un síndrome febril prolongado asociado a infección por M. pneumoniae que se complicó con encefalomielitis diseminada aguda. Se reportan otros seis casos con manifestaciones neurológicas: meningitis aséptica (1), meningoencefalitis (1), síndrome de Guillain Barré (1) y parálisis facial (3). La patogenia de las complicaciones neurológicas asociadas con infección por M. pneumoniae es aún desconocida, planteándose que algunas se deben a invasión directa del SNC y aquellas con pródromo prolongado, como encefalomielitis diseminada aguda, síndrome de Guillain Barré y mielitis transversa, obedecerían probablemente a fenómenos autoinmunes. En nuestro medio, en ausencia de RPC para confirmar el diagnóstico de esta infección, éste se fundamenta en la presencia de anticuerpos IgM o ascenso de IgG específica. La utilidad de los antimicrobianos en el control de estas manifestaciones neurológicas es discutida postulándose el uso de terapia inmunomoduladora.

\section{Bibliografía}

1.- Smith R, Eviatar L. Neurologic manifestations of Mycoplasma pneumoniae infections: diverse spectrum of diseases. A report of six cases and review of the literature. Clin Pediatr 2000; 39 (4): 195-201.

2.- Koskiniemi M. CNS manifestations associated with Mycoplasma pneumoniae infections: summary of cases at the University of Helsinki and review. Clin Infect Dis 1993; 17 Suppl 1: S 52-7.

3.- Smith C, Sangster G. Mycoplasma pneumoniae meningoencephalitis. Scand J Infect Dis 1972; 4: 6971.

4.- Abele-Horn M, Franck W, Busch U, Nitschko H, Roos R, Heesemann J. Transverse myelitis associated with Mycoplasma pneumoniae infection. Clin Infect Dis
1998; 26: 909-12.

5.- Mattson D H. Postinfectious encephalomyelitis. In: Gilman S. (Ed) Medlink Neurobase. San Diego. Arbor Publishing. $2^{\mathrm{a}}$ edition 2000.

6.- Lerer R J, Kalavsky S M. Central nervous system disease associated with Mycoplasma pneumoniae infection. Pediatrics 1973; 52 (5): 658-67.

7.- Bitnun A, Ford-Jones E L, Petric M, Mac Gregor D, Heurter H, Nelson S et al. Acute childhood encephalitis and Mycoplasma pneumoniae. Clin Infect Dis 2001; 32 (12): 1674-84.

8.- Keegan B M, Lowry N J, Yager J Y. Mycoplasma pneumoniae: a case of coma in the absence of meningoencephalitis. Pediatr Neurol 1999; 21 (5): 822-5.

9.- Fernández C V, Bortolussi R, Gordon K, Lee S H, Gatien J G, Shahdrabadi M S. Mycoplasma pneumoniae infection associated with central nervous system complications. J Child Neurol 1993; 8 (1): 27-31.

10.- Abramovitz P, Schuartzman P, Harel D, Lis I, Naot Y. Direct invasion of the central nervous system by Mycoplasma pneumoniae: a report of two cases. J Infect Dis 1987; 155 (3): 482-7.

11.- Nasr J T, Andriola M R, Coyle P K. ADEM: literature review and case report of acute psychosis presentation. Pediatr Neurol 2000; 22 (1): 8-18.

12.- Murray P, Kobayashi G, Pfaller M, Rosenthal K. Capítulo 37. Mycoplasma y Ureaplasma. Microbiología Médica. Segunda edición. Madrid, España. Harcourt Brace de España S.A. 1997. Pág 353-8.

13.- Cimolai N, Cheong A C. An assessment of a new diagnostic indirect enzyme immunoassay for the detection of anti Mycoplasma pneumoniae Ig M. Ann J Clin Pathol 1996; 105: 205-9.

14.- Waris M E, Toikka P, Saarinen T, Nikkari S, Meurman $\mathrm{O}$, Vainionpaa $\mathrm{R}$ et al. Diagnosis of Mycoplasma pneumoniae pneumonia in children. J Clin Microbiol 1998; 36 (11): 3155-9.

15.- Rodríguez S, Martínez M A. Utilidad clínica de una prueba diagnóstica en infecciones por Mycoplasma pneumoniae. Rev Pediatría 1996; 39: 69-73.

16.- Apak R A, Kose G, Anlar B, Turanli G, Topaloglu H, Ozdirim E. Acute disseminated encephalomyelitis in childhood: report of 10 cases. J Child Neurol 1999; 14 (3): 198-201.

17.- Nishikawwa M, Ichiyama T, Hayashi T, Ouchi K, Furukawa S. Intravenous immunoglobulin therapy in acute disseminated encephalomyelitis. Pediatr Neurol 1999; 21 (2): 583-6.

18.- Straussberg R, Schenfeld T, Weitz R, Karmazyn B, Harel L. Improvement of atypical acute disseminated encephalomyelitis with steroids and intravenous immunoglobulins. Pediatr Neurol 2001; 24 (2): 139-43.

19.- Mostafapour S P, Enzmann D, North W, Hahn J S. Brainstem multiple sclerosis in an 11-year-old child presenting as acute disseminated encephalomyelitis. J Child Neurol 1995; 10 (6): 476-80.

Correspondencia a:

Ana Chávez Polanco

E-mail: anachavez@mi.cl 